\title{
Current Patterns of Prehospital Trauma Care in Kampala, Uganda and the Feasibility of a Lay-First-Responder Training Program
}

\author{
Sudha Jayaraman · Jacqueline R. Mabweijano - Michael S. Lipnick • \\ Nolan Caldwell · Justin Miyamoto - Robert Wangoda - Cephas Mijumbi • \\ Renee Hsia $\cdot$ Rochelle Dicker $\cdot$ Doruk Ozgediz
}

(C) Société Internationale de Chirurgie 2009

\begin{abstract}
Background Uganda currently has no organized prehospital emergency system. We sought to measure the current burden of injury seen by lay people in Kampala, Uganda
\end{abstract}

S. Jayaraman

Department of Surgery, University of California San Francisco, 513 Parnassus Ave, S321, San Francisco, CA 94118, USA

J. R. Mabweijano $\cdot$ R. Wangoda

Department of Accident and Emergency,

Mulago Hospital and Makerere University, Kampala, Uganda

M. S. Lipnick

Department of Medicine, Brigham and Women's Hospital,

75 Francis Street, Boston, MA 02115, USA

N. Caldwell $\cdot$ J. Miyamoto

School of Medicine, Office of Medical Education,

University of California San Francisco, San Francisco, CA, USA

C. Mijumbi

Department of Anaesthesia, Mulago Hospital and Makerere

University, Kampala, Uganda

R. Hsia

Department of Emergency Medicine, University of California San Francisco, 505 Parnassus Avenue, Room M-24,

San Francisco, CA 94143-0203, USA

R. Dicker

Department of Surgery, San Francisco General Hospital,

Ward 3-A, 1001 Potrero Avenue, San Francisco, CA 94110,

USA

D. Ozgediz ( $\square)$

Division of Pediatric Surgery, Hospital for Sick Children,

University of Toronto, 555 University Avenue, Toronto,

ON M5G 1X8, Canada

e-mail: dozgediz@hotmail.com and to determine the feasibility of a lay first-responder training program.

Methods We conducted a cross-sectional survey of current prehospital care providers in Kampala: police officers, minibus taxi drivers, and Local Council officials, and collected data on types and frequencies of emergencies witnessed, barriers to aid provision, history of training, and current availability of first-aid supplies. A context-appropriate course on basic first-aid for trauma was designed and implemented. We measured changes in trainees' fund of knowledge before and after training.

Results A total of 309 lay people participated in the study, and during the previous 6 months saw 18 traumatic emergencies each; 39\% saw an injury-related death. The most common injury mechanisms were road crashes, assault, and burns. In these cases, $90 \%$ of trainees provided some aid, most commonly lifting (82\%) or transport (76\%). Fifty-two percent of trainees had previous first-aid training, $44 \%$ had some access to equipment, and $32 \%$ had ever purchased a first-aid kit. Before training, participants answered $45 \%$ of test questions correctly (mean \%) and this increased to $86 \%$ after training $(p<0.0001)$.

Conclusions Lay people witness many emergencies and deaths in Kampala, Uganda and provide much needed care but are ill-prepared to do so. A context-appropriate prehospital trauma care course can be developed and improve lay people's knowledge of basic trauma care. The effectiveness of such a training program needs to be evaluated prospectively.

\section{Introduction}

Injury, an increasingly significant public health issue worldwide, accounts for up to $16 \%$ of the global burden of 
disease, with road traffic crashes, in particular, on the rise [1]. By 2030, road traffic crashes are predicted to be the eighth-leading cause of death and fourth-leading cause of disability-adjusted life years worldwide [2,3]. Currently, more than $90 \%$ of road traffic injury deaths occur in developing countries [4-6] where approximately $80 \%$ of injury deaths occur in the prehospital setting [7]. This disproportionate burden is projected to increase as developing countries rapidly urbanize and motorize without associated improvements in injury prevention and control $[8,9]$.

Trauma system development in high-income countries has reduced preventable deaths, including those from road traffic injuries, by $50 \%$ in recent decades [10]. It is estimated that improved trauma systems in low- and middleincome countries could avert one to two million deaths in severely injured patients [7]. However, injury research in low-income countries, particularly intervention-based research, has been grossly neglected in the global public health arena.

Uganda, like many other low- and middle-income countries, suffers from a severe injury epidemic. The 1995 national burden of disease study showed that injury was among the top six causes of death in more than half of the districts studied [11, 12]. Within the capital city of Kampala, Uganda's national referral hospital, Mulago Hospital, handles many more injured patients than any other health facility in the country. Approximately 6,000 injured patients are treated there every year [12]. However, based on community surveys from other urban sub-Saharan African settings, an estimated 4,000 patients do not reach the hospital [13]. As many as $90 \%$ of the injured patients who reach Mulago Hospital are mildly injured, which suggests that severely injured patients are unable to access emergency care [14].

Despite this great need for emergency care and substantial evidence to support trauma system development, Kampala has no formal prehospital emergency system. Injured patients arrive at the hospital by any means possible: car, motorcycle, minibus taxi, police vehicle, or on foot. Figure 1 depicts the manner by which most patients arrive at the hospital when transported by the police. Less than $5 \%$ arrive by ambulance because few exist and these are mostly privately owned and prohibitively expensive. Furthermore, one in three patients arrive at Mulago beyond the first hour after the injury, the "golden hour," during which expedient treatment would greatly increase survival [12]. Currently, prehospital care is given on a voluntary basis, by police or minibus taxi drivers in road-related emergencies and community leaders, called Local Council officials, in emergencies near the home. However, little is known about the burden of emergencies in Kampala and

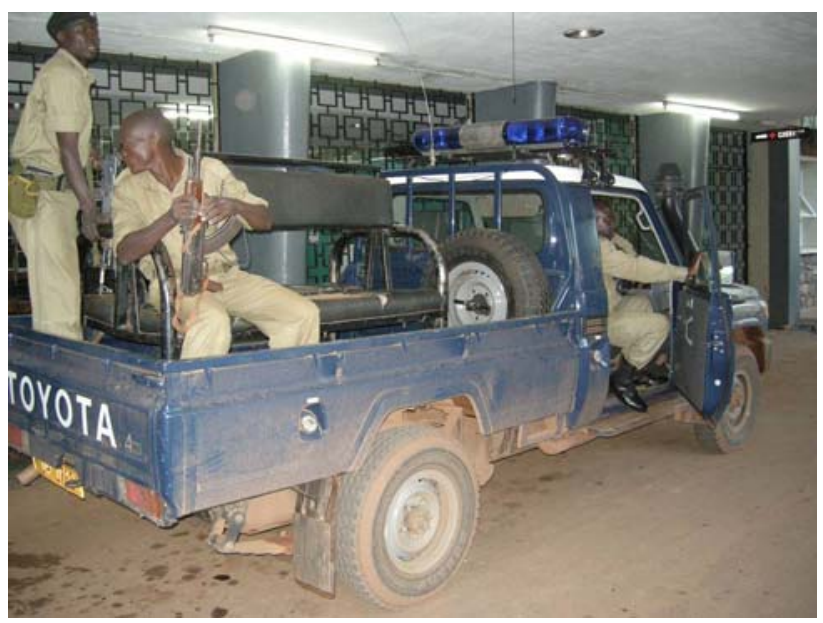

Fig. 1 Police vehicle for patient transport outside hospital emergency room: the patient is generally brought under the seats in the back of the pickup truck

the capacity of this ad hoc network of lay first-responders to provide such care.

In settings where formal emergency systems are absent, the World Health Organization's (WHO) Essential Trauma Care and Prehospital Care guidelines recommend training lay people as first-responders $[15,16]$. These recommendations, also endorsed by the World Bank, are primarily based on evidence from first-aid provided by villagers in conflict-ridden Northern Iraq, Cambodia, and urban Ghana [17-20]. Lay first-responder training, implemented in Ghana, showed encouraging results for feasibility in the African setting [19].

We hypothesized that lay people in Kampala encounter and provide care for a substantial burden of emergencies, particularly trauma, despite many challenges. We also hypothesized that it is feasible to design and implement a simple context-appropriate lay first-responder training program that improves lay people's knowledge of prehospital trauma care.

\section{Methods}

To measure feasibility, we sought to determine whether a context-appropriate course could be designed by stakeholders, whether the course was relevant to trainees based on their experiences, and whether fund of knowledge would improve with training. We developed a modified basic first-aid curriculum for the Ugandan context based on the Ghanaian course [19] and planned to enroll 300 Ugandan police officers, taxi drivers, and Local Council officials in the training program. Institutional Review Board approvals were obtained at the University of 
California, San Francisco, Mulago Hospital, and the Uganda National Council of Science and Technology for this study.

\section{Stakeholders}

To assess interest in the study, meetings were held with leaders of groups who currently plan health services and those who provide prehospital care in Kampala. These included the Kampala Police Department, the Local District Government, and the Taxi Operators and Drivers Association, as well as the Injury Control Center-Uganda, the Ministry of Health, the Kampala City Council Department of Health, and physicians from Mulago Hospital. All groups uniformly supported the need for such a study. The Ugandan Red Cross and selected Certified FirstAid Trainers participated in these discussions and in conduct of the study.

\section{Participants}

Previously published data on injury patterns in Kampala indicate that $58 \%$ of injuries occurred on the roads and $29 \%$ in or near the home [12]. Based on this injury distribution, trainees were sought from the police, minibus taxi drivers, and Local Council officials by convenience sampling to ensure that participants who were identified by their supervisors as most likely to engage in prehospital trauma care were recruited. Local council members work at the grassroots community levels. They take charge of local administration, keeping law and order, defense, healthcare, and self-help initiatives, and they live among the people they lead. Often they are village elders, opinion leaders, or the enlightened. There are five local council (LC) levels as follows: village (LC I), subparish (LC II), parish or division (LC III), county (LC IV), and district (LC V). LC Is were included in this study. All study participants gave informed consent before taking part in the study.

\section{Setting}

This study was conducted in Kampala (population: 1.2 million, area of 80 square miles [21]) where the most common languages are English and Luganda. A catchment area was defined encompassing four of the five administrative divisions in Kampala (within 20 square miles of Mulago Hospital). The fifth division was excluded because of its high density of hospitals that provide emergency care, although fee-for-service. The five government-run Health Centers (community clinic equivalents) in the catchment area were sensitized about our study. Brief needs assessments were conducted to understand the staffing and resources available to treat emergencies at these clinics as well.

Study design

\section{Cross-sectional survey}

To determine the current burden of emergencies encountered by trainees, a cross-sectional survey using semistructured one-on-one interviews was conducted before training. Data were collected on types of emergencies and deaths witnessed by trainees, frequency and modes of intervention, barriers to intervention, baseline first-aid knowledge, previous training, and current access to first-aid equipment. The survey questionnaire was developed in English and Luganda by study investigators and pilot-tested twice (Table 1). Additionally, all trainees were asked to describe in narrative form the last emergency that they encountered.

\section{Training course curriculum and format}

Until recently, first-aid courses available in resource-constrained settings were based on courses in high-income countries and included topics such as cardiopulmonary

Table 1 Content areas covered by cross-sectional survey questionnaire

Trainee identification and demographics

Current job category and years worked in current job

Level of education

Previous first-aid training

Access to any first-aid equipment now

History of having bought a first-aid kit

Willingness to pay for a basic first-aid kit

Emergencies and deaths seen in preceding 6 months

Mechanisms of traumatic emergencies and number witnessed

- Frequency of help provided in traumatic emergencies and type of help provided

- Reasons for not providing help

- Transport to hospital versus clinic

- Number who died before reaching health facility

Mechanisms of medical emergencies witnessed

- Frequency of help provided

- Reasons for not providing help

- Transport to hospital versus clinic

- Number who died before reaching health facility

Location where emergencies are usually taken: hospital, clinic, home, healer, etc., and reason

Average time to the closest hospital

Ever used an emergency number (police)

Confidence at providing first-aid at baseline (before course) 
resuscitation (CPR), which are unlikely to be effective in these settings. For the Ugandan context, we modified the Ghanaian basic first-aid curriculum based on our understanding of the challenges to current prehospital care provided in Kampala and the perceived field utility of skills (Table 2) [18]. Key areas included scene management, immediate care, and transport. The curriculum covered universal precautions, primary survey, scene management, bleeding control, airway control, recovery position, safe lifting and transportation of injured victims, and splinting fractures. Triage training was provided to minimize the number of minor injuries brought to an already congested emergency department at Mulago Hospital and to increase the major emergencies brought to Mulago instead of the Health Centers. Training did not include CPR because it was unlikely to be effective in this context due to resource constraints, and it would potentially expose lay people to unnecessary infectious risks. Slight modifications to the curriculum reported in Ghana included the use of a tarpaulin to transport patients, specific emphasis on positioning patients in police (trucks) and commercial vehicles, specific emphasis on use of cardboard for splinting, and less emphasis on extrication in the Ugandan course. As the following describes, we provided a kit in this course, which was not provided in the Ghanaian course.

The 1-day course was conducted in English for the police and in Luganda for the taxi drivers and Local
Council officials and was held five times. Each day had a didactic component given by JRM and five hands-on training sessions led by local Ugandan Red Cross Certified First-Aid Instructors and physicians (DO, ML, JRM, CM, $\mathrm{RW})$. The course required minimal literacy skills because the didactic session was limited to 1 hour and slides from this session were distributed and were primarily pictographic, and this was a highly interactive session. In addition, several short instructional videos were used to demonstrate skills, such as bleeding control and use of the recovery position. Those who were unable to read the slides were assisted by interpreters. There was no required reading material for the course, and the five hands-on skill sessions composed the majority of the course. The taxi drivers also attended a session on safe driving practices given by their supervisors. The class size was kept to 50 to 100 trainees to facilitate hands-on training. All training materials were simple and easily obtainable in Kampala. To obtain course certification, trainees had to demonstrate competence at every station to the instructor.

Fund of knowledge was assessed before and after the course in the appropriate language using five multiplechoice questions covering the core areas of scene safety, bleeding control, airway evaluation, recovery position for unconscious patients, and safe transportation (Table 3). This questionnaire was developed by study investigators, stakeholders, and trainers and was further refined through
Table 2 Challenges to emergency care in Kampala
Scene

- Police cannot leave the scene of a road traffic crash

- Police do not allow anyone who was involved in situation to leave the scene

- Police frequently do not allow victims to be taken to medical facilities until after the crash investigation

- Many lay people do not assist in emergencies for fear that they will be implicated in the crime and that police will arrest them

- Lack of a call system - all emergency calls go to police who do not have an ambulance service or training beyond basic first-aid

Immediate care

- Police state they would not handle patients without gloves

- There is no access to first-aid kits and materials for police

- Taxi drivers are mandated to have small first-aid kits in their vehicles, but no recommendations exist for kit content and no plans exist for inspecting them or replenishing supplies

- Most patients arrive with open, bleeding wounds

Transport

- Unconscious patients are brought lying on their backs without airway protection

- No backboard or materials are available for safe transport

- Police bring patients in pickup trucks

- Taxi drivers sometimes bring people to the hospital as good Samaritans but often ask patients to pay for transport

Definitive care

- Hospital and clinics at times are slow to intervene, particularly at night or weekends when staffing is low

- Clinics often do not have access to gloves, gauze, and suture to address minor injuries

- No mechanism exists to transport a critically ill patient from clinics to Mulago Hospital 
Table 3 Questionnaire used to assess fund of knowledge

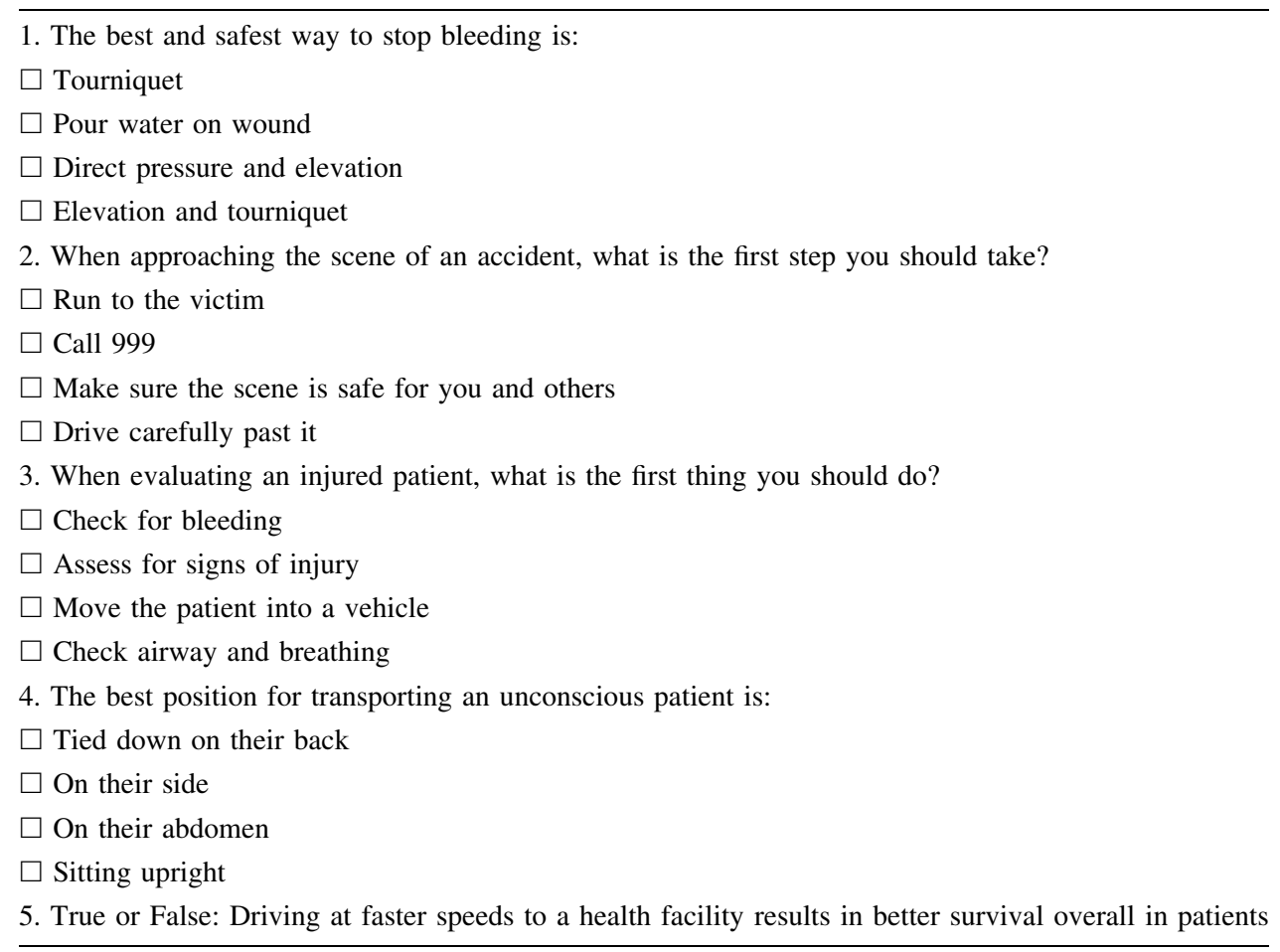

in-depth interviews with members of each of the three training groups. Subsequently, the questionnaire was pilot tested with a random selection of 10-15 members of each of the three training groups. The same questionnaire was administered on the morning before and at the conclusion of the course. Before the adjournment of the course, the correct and incorrect answers to the questions were reviewed as a group.

The five 45-min skill sessions each respectively covered 1) scene safety and universal precautions, 2) bleeding control, 3) airway management and the recovery position, 4) splinting, and 5) safe moving, rudimentary triage principles, and safe transportation. The skills sessions were organized in small groups of 10-15 trainees with a pair of the local Ugandan Red Cross Instructors and one of the study physicians leading each session. Trainees were each required to demonstrate the respective skills with equipment from the kits that were provided to each of the trainees at the end of the course. For example, at the universal precautions station, trainees practiced using gloves and protection from blood and body fluids; at the bleeding control station trainees practiced applying pressure dressings with gauze and triangular bandages; they practiced moving patients into the recovery position at the airway station; they splinted arms and legs with cardboard boxes at the splint station; and they moved each other from an injury scene to the vehicle using a tarpaulin at the moving station. At every skills station, only the equipment provided in the kits was used to maximize trainees' familiarity with the equipment that they would be provided with at the end of the course, and at each station skills from other stations were integrated.

After completing the course, each trainee received a certificate of completion, a custom-made arm band, an identity card, and a placard, with quick tips, to place on their transport vehicles (Fig. 2). These measures were used to give trainees credibility in society as they performed first-aid in the field because they are not known as medical professionals, and to make them easily identifiable to the general public.

\section{Training course supplies and costs}

Each participant received a first-aid kit and instructions on how to contact the study team to replenish the kit. Each kit was a $1.5-\times 1-\times 1$-foot duffel bag with 20 pairs of gloves, gauze, cotton, two triangular and two crepe bandages, medical tape, cardboard for use as splints, a reusable piece of tarpaulin for use as a modified stretcher, and bleach to clean the tarpaulin after each use. All items, including the bags, were purchased and assembled locally. Participants were taught how to use each item appropriately and effectively. The cost of each kit was \$16 (materials: \$13, bag: \$3; UGX 25,600) and was less than one quarter of the cost of commercially available first-aid kits in Kampala, which range from $\$ 62.50$ to $\$ 187.50$ (UGX 100,000 to 300,000 ). The total cost of the 5 courses offered to the 307 trainees, inclusive of kits, was approximately $\$ 8,300$ or 
Fig. 2 Vehicle placard, arm band, and identification card provided to each trainee upon completion of the first responder for trauma course

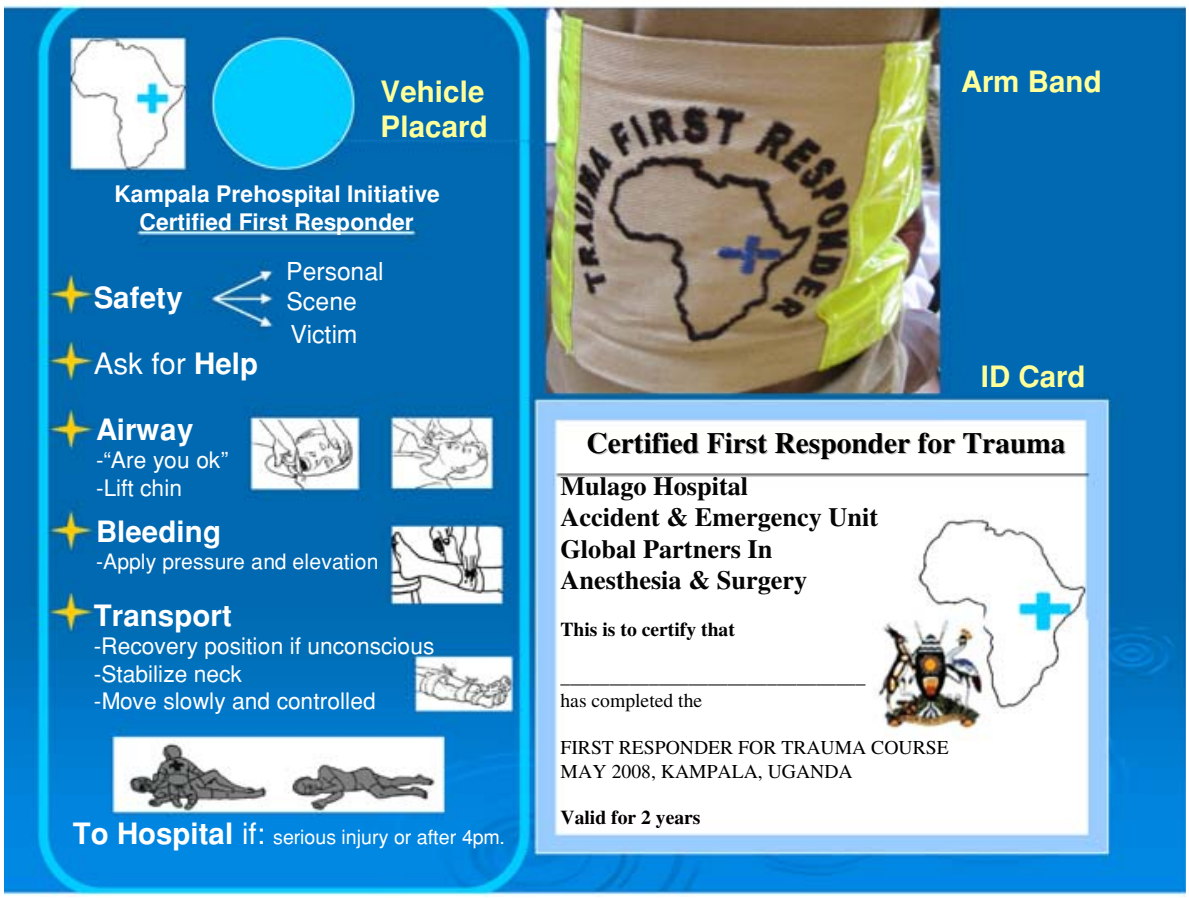

$\$ 27 /$ trainee (total: $\$ 1,600$ trainee salary to compensate for time off work; $\$ 650$ trainer salary; $\$ 450$ facility rental; $\$ 40$ materials; $\$ 4,900$ kits).

\section{Statistical analysis}

Descriptive analysis was done for the cross-sectional survey. Odds ratios and 95\% confidence intervals were calculated as appropriate. Paired $t$ tests were used to compare fund of knowledge tests before and after training. $\chi^{2}$ tests and logistic regression were used to conduct subgroup analyses. All analyses were done using Stata version 10 (College Station, TX, 2007). Based on the results of the cross-sectional survey, the Local Council officials and minibus taxi drivers were similar with respect to their ability to help in emergencies, history of training, and access to first-aid equipment. These groups were grouped to increase the power of comparative analysis, and subgroup analysis was conducted to evaluate the effect of being a police officer on all outcomes.

\section{Results}

Of the 309 trainees who participated in the study, $87 \%$ were men and the most common age group was 2635 years $(39 \%)$. The largest cohort was police officers $(57 \%)$, followed by taxi drivers $(30 \%)$ and local government officials (13\%). Overall, 33\% had been working in their current jobs for more than 10 years and $26 \%$ reported having started their current jobs within the last year. Most participants $(87 \%)$ had some secondary education, but the reported range varied from none $(1 \%)$ to advanced, postsecondary education $(34 \%)$.

Emergencies witnessed by study trainees and current ability to provide emergency care

Characteristics of the trainees, their function, and selected descriptions of their experiences are outlined in Tables 4 and 5. Trainees reported witnessing an average of 18.4 traumatic emergencies each during the previous 6 (median, 11) months. The most common were road crashes, assault, burns, and falls. Trainees mostly saw 1-5 road crashes per person $(47 \%, \mathrm{n}=142)$, although $6 \%$ saw more than 20 . In traumatic emergencies, $90 \%$ reported providing some assistance. Of 236 trainees responding, 39\% reported witnessing an injury-related death, most of whom saw 1-5 deaths each.

The most common medical emergencies witnessed were people who were unconscious, febrile, or had pregnancyrelated problems. More than $70 \%$ of trainees had seen at least one medical emergency in the past 6 months, and $90 \%$ of all trainees had provided some help in such an emergency. Of 164 trainees who reported witnessing medical emergencies, $26 \%$ had seen a death related to one of these medical conditions in the last 6 months, with most seeing $1-5$ deaths each.

Ninety trainees $(32 \%)$ had ever purchased a first-aid kit with $53 \%(\mathrm{n}=42)$ reportedly spending more than $\$ 6.25$ 
Table 4 Current patterns in prehospital emergencies in Kampala

Emergencies witnessed by 309 participants during previous 6 months

Most common traumatic emergencies seen:

- Road crashes $\quad 90 \%$

- Assault $\quad 67 \%$

- Burns $\quad 45 \%$

In these situations, $90 \%$ of trainees reported stopping to provide some assistance.

Most common nontraumatic emergencies seen:

- Unconscious victim $\quad 57 \%$

- Febrile victim $\quad 52 \%$

- Obstetric emergency $39 \%$

More than $90 \%$ of trainees had stopped to provide some help in such an emergency.

Deaths witnessed by trainees during previous 6 months

- Saw injury-related death (of $n=236$ )

- Saw 1-5 deaths per person

- Saw 6-10 deaths per person

- Saw 11-20 deaths per person

Saw $>20$ deaths

- Saw noninjury death (of $n=164$ )

- Saw 1-5 deaths per person

Saw 6-10 deaths per person

Current prehospital care and barriers to provision

Most common aid given:

$\begin{array}{ll}\text { Lifting/moving } & 82 \%\end{array}$

$\begin{array}{ll}\text { Transport to hospital } & 76 \%\end{array}$

Main concern when aid was not given:

- Lack of equipment $\quad 44 \%$

- Lack of knowledge $\quad 37 \%$

Current capacity

$\begin{array}{ll}\text { Previous first-aid training } & 52 \%\end{array}$

Previous access to equipment $44 \%$

$\begin{array}{ll}\text { Ever purchased a first-aid kit } & 32 \%\end{array}$

$\begin{array}{ll}\text { Spent more than UGX } 10,000(\$ 6.25) \text { on kit } & 53 \%\end{array}$

Median willingness to pay per kit $\quad$ UGX 5,001-10,000 (\$3.125-\$6.25)

(UGX 10,000) per kit. Of the 208 who had not bought a kit, they were willing to pay $\$ 3.125$ to $\$ 6.25$ (median, UGX 5,001-10,000) per kit, which is less than the cost of the study kit (\$16).

Fund of knowledge of trainees before and after first-aid course

Fund of knowledge scores increased from $45 \%$ correct (mean score, $2.2 \pm 1.18$ (SD)) before training to $86 \%$ $(4.3 \pm 0.94)$ after training $(n=219$ pairs; $p<0.0001)$. Significant improvements were seen for every question. The greatest were in recovery position (28-96\%) and safe transportation (31-87\%), which are encouraging because protecting the airway and not causing road crashes en route to the hospital may be lifesaving $(p<0.0001)$.
Understanding of bleeding control increased the least (36-74\%), although it was still significant.

Subgroup analyses

The police were 3.6 times more likely to have completed more years of school than the other trainees $(p<0.0001)$. In addition, based on self-reports, police trainees were 9.2 times more likely than the others to provide any help at the scene of an emergency, 3.7 times more likely to have previous first-aid training, but 6.3 times less likely to have access to a first-aid kit (Table 6). After training, the police were likely to score higher on the fund of knowledge test compared with the other trainees and had 3.8 times the odds of answering all questions correctly compared with others. 
Table 5 Selected descriptions of the most recent emergency witnessed by trainees before the training course

"The emergency I encountered, a car over turned and people got injuries; two broke their hands and what I did was to get sticks and I put back the bones together after which I tied the sticks around the broken hands and then I took them to a nearby hospital."

"I was going to Mbarara and I met an accident. A bus that was coming from Mbarara going to Kampala had crashed, but because I did not know anything, I just carried two victims, put them in my car and took them to Mbarara hospital without any first-aid. I thought I knew something but in actual sense I did not know anything."

"I found a boda [motorbike] that had knocked a child... I stopped and carried the child to side of the road then I checked whether it was breathing and it was breathing but it had a wound on the head, so I got cotton and iodine from my first-aid kit and washed the wound and I tied [it] with plaster [medical tape]. After I took the child to Mulago and they wanted to detain me but I explained to them that it was not me who knocked him, it was the boda."

"I met an accident and on this day I faced a problem: I was helping these people but police detained me [thinking] that [I] was the one who caused the accident and I actually spent a whole day at the police post being interrogated."

"At clock tower there was a serious accident where a Toyota Hiace collided with the trailer. The driver of the Toyota and other two passengers got injured at the scene, therefore, I first rushed the victims to Nsambya for first-aid but use of private means .... I could not carry out first-aid because I did not have the [equipment]."

"I found a road traffic guide on the road collapsed, and what I did was to kneel down and I looked for the pulses and after I blew air in his nose and mouth."

"A vehicle knocked a motorcycle, we came to help, but one person had died and the other one had blood coming out of him. We made him lay down on his stomach, and when blood stopped coming, we took him to a hospital."

"I was home and a young boy was playing. When he was running he fell near a charcoal store and there was boiling beans. So what I did, I run quickly and applied oil and sugar on the injured part, then after we got a boda and rushed him to Rubaga hospital."

Table 6 Comparison of police cohort to the combined taxi driver/local council cohort

\begin{tabular}{lcc}
\hline Likelihood of having characteristic & Odds ratio (95\% CI) & Significance $(p$ value $)$ \\
\hline Any education at baseline & $2.0(1.6-2.5)$ & $<0.01^{*}$ \\
Previous first-aid training & $3.7(2.2-6.2)$ & $<0.01^{*}$ \\
Ability to provide immediate help on scene & $9.2(3.2-26.2)$ & $<0.01^{*}$ \\
Access to any first-aid equipment at baseline & $0.16(0.1-0.3)$ & $<0.01^{*}$ \\
Odds of answering all questions correctly after training & $3.8(2.2-6.7)$ & $<0.01^{\dagger}$ \\
\hline
\end{tabular}

$* \chi^{2}$ test; ${ }^{\dagger}$ Logistic regression

\section{Discussion}

Lay people currently witness many emergencies and deaths in Kampala and provide much-needed prehospital emergency care despite being grossly ill-equipped to do so. Our study indicates that a context-appropriate first-aid course can be developed to provide basic training in prehospital trauma care for this population. This is supported not only by the results of the surveys, but also by the narratives provided by all trainees. As one of the first attempts to describe the impact of rapid urbanization and motorization on emergency medical needs in Kampala, our study fills a critical gap in the understanding of injury epidemiology and the informal provision of prehospital services.

Our findings have several major implications for policymakers and donor organizations financing health care in Uganda. There is a clear need for a more organized prehospital emergency medical system (EMS) in Kampala based on the numbers of emergencies and deaths encountered by lay people. However, training and supplies were not available to many: only $52 \%$ of trainees had ever had first-aid training, $44 \%$ had access to some first-aid materials, and few were willing to pay much for first-aid supplies. The police were more likely to be trained in first-aid but less likely to be equipped to use their first-aid skills. In contrast, taxi drivers who were mandated by law to carry first-aid supplies in their vehicle were less likely to be trained to use them. Addressing this inefficiency alone could substantially increase the effectiveness of informal lay first-responders in Kampala. Additionally, the increases in fund of knowledge after our course were encouraging overall and particularly significant for the police trainees. Because the police have, on average, completed a higher level of education than the taxi drivers, this was expected to some degree and suggests that the course could potentially be slightly modified in the future depending on the target group.

The critical step to making our program feasible and relevant to participants was a series of meetings with the multidisciplinary group of stakeholders. These meetings identified the greatest current challenges to prehospital trauma care in Kampala (Table 2), which allowed us to 
design a context-appropriate program that would be relevant and useful for participants. Whereas the core medical skills of such a program may be consistent across settings, if this project were replicated in other countries, addressing the context-specific challenges will be crucial to developing a relevant and effective training program. For example, improving relationships between the police, taxi drivers, local council officials, and health facility personnel was critical to this program.

Limitations of our study include selection and information bias and validity of the training program. The experiences of study subjects may not be truly representative of all members of the three target cohorts because we used convenience sampling. In addition, recall and interviewer bias may have contributed to over-reporting of witnessed emergencies and care that is provided. The course content has not been previously validated in this setting. Topics were modified from previously reported curricula, which had been adapted from validated Red Cross first-aid courses [19]. Our modifications may affect the validity and generalizability of this course to other settings. Based on our findings, more emphasis on bleeding control is needed in future courses. Additionally, our assessment of the need for specific supplies may be flawed. The contents of the first-aid kit were identified based on perceived utility in the field and from stakeholders' experiences (e.g., lack of gloves significantly deters police from providing emergency aid) because there are no published reports on what an effective first-aid kit in a resourceconstrained setting should contain. Finally, the five-question fund of knowledge test was not tested for all aspects of validity. Thus, it may not have captured our trainees' true understanding of basic first-aid for trauma or may have been too brief to reflect this knowledge. Nonetheless, we feel that the questionnaire covered key content areas as determined by investigators and stakeholders and that the preliminary validation done for this pilot course was adequate to draw possible conclusions of key knowledge deficits. We plan to more formally validate this initial instrument in future evaluations.

Despite the above limitations, our study leaves several areas open to further research. First, effectiveness and impact of the course need to be measured prospectively. Knowledge retention may be an important issue when trainees have no baseline medical background. Fund of knowledge tests and refresher trainings need to be conducted to evaluate and aid retention. The need and method for restocking supplies is another important issue. We are in the process of prospectively following this trained cohort to assess knowledge retention, skill use, and confidence and plan to evaluate the effectiveness of this intervention. Additionally, measuring the impact of training programs such as this on morbidity and mortality at the population level is critical for policy-makers but requires a larger and more robust study. Further research on this question could build a stronger case for prehospital emergency services. We plan to disseminate these results locally through all stakeholders and the Ministry of Health, as well as internationally. Funding from public sources as well as donor partners, along with private sources will be sought to expand and sustain the program.

Second, the injury epidemiology that we reported needs to be cross-checked with facility- and population-based data. This will help to determine the magnitude of preventable prehospital deaths as well as help to define the best ratio of first-responders to population, which is not clear at this time. The WHO estimates, based on data from a conflict setting, that as many as 7,500 lay first-responders should be trained for every one million people; however, the applicability of these figures to nonconflict contexts is unclear [20, 22, 23].

Most importantly, good trauma care is not a substitute for effective injury prevention. Organizations, such as the Injury Control Center - Uganda, need more support from the government and the global donor community to engage in research activities on injury prevention and control so that many of these questions can be answered at the local level.

\section{Conclusions}

The lack of formal prehospital emergency services in Kampala, Uganda is an important and grossly neglected issue. Lay people bear much of the burden of providing care on the scene, despite having little formal training or equipment to do so. This study shows that a contextappropriate, 1-day, basic first-aid course for lay people can be developed and implemented in this setting. The knowledge and skills acquired from such a course, coupled with locally available supplies, may form a useful first step toward formalizing emergency medical services in Kampala.

Acknowledgments The authors are grateful for unrestricted project funding from the Hellman Foundation and The Laura Case Trust to pursue this study, and sincerely thank the following contributors who gave valuable assistance at during various stages of this project: Dr. James Suozzi, Moses Dumba from the Ugandan Taxi Operators and Drivers Association; Red Cross First-Aid Instructors: Robert Okuyat, Juliet Kiyimba, Ivan Luwaga, and Daniel Nsubuga; Red Cross Volunteer: Yusuf Kimbowa; Sarah Nakitto, Research Coordinator, Chris Hartley-Sharpe from London Ambulance Service; Dr. Charles Mock and Dr. Olive Kobusingye. The authors also thank the UCSF Department of Surgery Scientific Publications Manager, Pamela Derish, for editorial support. This project was conducted using an unrestricted gift from the Hellman Family Foundation, which had no role in study design, analysis, writing of the report, or decision to submit for publication. 


\section{References}

1. Lopez AD, Mathers CD, Ezzati M, Jamison DT, Murray CJ (2006) Global and regional burden of disease and risk factors, 2001: systematic analysis of population health data. Lancet 367(9524):1747-1757

2. Mathers CD, Loncar D (2030) Projections of global mortality and burden of disease from 2002 to 2030. PLoS Med 3(11):e442

3. The global burden of disease: 2004 update. Geneva: WHO2008

4. Hofman K, Primack A, Keusch G, Hrynkow S (2005) Addressing the growing burden of trauma and injury in low- and middleincome countries. Am J Public Health 95:13-17

5. Murray CJL, Lopez AD (1996) The global burden of disease: a comprehensive assessment of mortality and disability from diseases, injuries, and risk factors in 1990 and projected to 2020. Harvard University Press, Cambridge

6. Murray CJL, Lopez AD (1996) Global health statistics: a compendium of incidence prevalence and mortality estimates for over 200 conditions. Harvard University Press, Cambridge

7. Mock CN, Jurkovich GJ, nii-Amon-Kotei D, Arreola-Risa C, Maier RV (1998) Trauma mortality patterns in three nations at different economic levels: implications for global trauma system development. J Trauma 44:804-814

8. WHO (2004) World report on road traffic injury prevention. World Health Organization, Geneva

9. Debas HT, Gosselin R, McCord C, Thind A (2006) Surgery. In: Jamison D, Breman J, Measham A, Alleyne G, Claeson M, Evans $\mathrm{D}$ et al (eds) Disease control priorities in developing countries, 2nd edn. Oxford University Press, New York

10. Mock C, Nguyen S, Quansah R, Arreola-Risa C, Viradia R, Joshipura M (2006) Evaluation of Trauma Care capabilities in four countries using the WHO-IATSIC Guidelines for Essential Trauma Care. World J Surg 30:946-956

11. Ministry of Health Epidemiology Unit C, Planning Unit (1996) Burden of disease, cost-effectiveness analysis and five year projections in thirteen districts of Uganda. Uganda Ministry of Health and United States Centers for Disease Control and Prevention, Entebbe, Uganda

12. Kobusingye OC, Guwatudde D, Owor G, Lett RR (2002) Citywide trauma experience in Kampala, Uganda: a call for intervention. Inj Prev 8:133-136
13. Mock CN, nii-Amon-Kotei D, Maier RV (1997) Low utilization of formal medical services by injured persons in a developing nation: health service data underestimate the importance of trauma. J Trauma 42:504-513

14. Kobusingye OC, Lett RR (2000) Hospital-based trauma registries in Uganda. J Trauma 48:498-502

15. Mock C, Lormand J, Goosen J, Joshipura M, Peden M (2004) Guidelines for essential trauma care. World Health Organization, Geneva

16. WHO (2005) Prehospital trauma care systems. World Health Organization, Geneva

17. Kobusingye O, Hyder A, Bishai B, Joshipura M, Romero Hicks E, Mock C (2006) Emergency medical services. In: Jamison D, Breman J, Measham A, Alleyne G, Claeson M, Evans D et al (eds) Disease control priorities in developing countries, 2nd edn. Oxford University Press, New York

18. Mock CN, Tiska M, Adu-Ampofo M, Boakye G (2002) Improvements in prehospital trauma care in an African country with no formal emergency medical services. J Trauma 53:90-97

19. Tiska MA, Adu-Ampofo M, Boakye G, Tuuli L, Mock CN (2004) A model of prehospital trauma training for lay persons devised in Africa. Emerg Med J 21:237-239

20. Husum H, Gilbert M, Wisborg T, Van Heng Y, Murad M (2003) Rural prehospital trauma systems improve trauma outcome in low-income countries: a prospective study from North Iraq and Cambodia. J Trauma 54:1188-1196

21. Kampala City Council District Profile. Kampala, Uganda. http://www.kcc.go.ug/city_council_of_kampala_directorates_ downloads.asp

22. Kobusingye O, Hyder A, Bishai B, Joshipura M, Romero Hicks E, Mock C (2006) Emergency medical systems. In: Jamison DT et al (eds) Disease control priorities in developing countries, 2nd edn. World Bank,

23. Husum H, Gilbert M, Wisborg T (2003) Training pre-hospital trauma care in low-income countries: the 'Village University' experience. Med Teach 25:142-148 